\title{
ELECTRICAL AND STRUCTURAL PROPERTIES OF OHMIC CONTACTS TO $n$-TYPE AND HIGH RESISTIVITY CdTe*
}

E. Kamińska ${ }^{a}$, A. PiotrowskA ${ }^{a}$, M. Guziewicz ${ }^{a}$, S. GierlotkA $^{b}$, E. PAPIS ${ }^{a}$, J. LUSAKOWSKI ${ }^{c}$, K. SZADKOWSKI ${ }^{c}$, S. KWIATKOWSKI ${ }^{d}$,

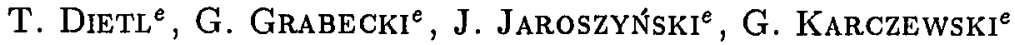
AND A.K. ZAKRZEWSKI ${ }^{e}$

\author{
${ }^{a}$ Institute of Electron Technology, Al. Lotników 32/46, 02-668 Warszawa, Poland \\ ${ }^{b}$ Unipress, Polish Academy of Sciences, Sokołowska 29/37, 01-142 Warszawa, Poland \\ 'Institute of Experimental Physics, Warsaw University \\ Hoża 69, 00-681 Warszawa, Poland \\ ${ }^{d}$ A. Soltan Institute for Nuclear Studies, Hoża 69, 00-681 Warszawa, Poland \\ e Institute of Physics, Polish Academy of Sciences \\ Al. Lotników 32/46, 02-668 Warszawa, Poland
}

The interaction between CdTe and In during the formation of an ohmic contact has been investigated. Emphasis is placed on the study of the effect of thermally induced sublimation of cadmium on electrical properties of contacts. Presented results prove the effectiveness of cap annealing and rapid thermal processing in fabrication of improved ohmic contacts with limited Cd losses during the contacting procedure.

PACS numbers: $73.40 . \mathrm{Ns}$

Metal/CdTe interfaces are playing an increasingly important role in the development of high performance devices for new and existing applications [1,2]. Despite of the wide interest, very little is known about the structure and interactions which fundamentally control the interfacial properties of these systems. Indium is a commonly used metal for ohmic contacts to $n$-type $\mathrm{CdTe}[3,4]$. However, conventionally fabricated indium contacts have two important drawbacks. First, metallization is highly inhomogeneous both laterally and vertically, which is unsuitable for submicron structures. Second, electrical properties are nonreproducible, especially in the case of lightly doped or compensated CdTe.

Our approach is to take the advantage of the ability of indium to make ohmic contacts to $n$-type CdTe and to apply the techniques of cap annealing and rapid thermal processing, previously exploited in the fabrication of ohmic contacts to III-V compound semiconductors.

*This work was supported by the grant of the State Committee for Scientific Research (Republic of Poland) No. 7 S201 02306. 
The substrates were either high resistivity CdTe crystals grown by modified Bridgman method or $n$-type CdTe:In layers, 3-8 $\mu \mathrm{m}$ thick, grown by MBE on $n$-type or SI (100) GaAs. To reveal an undamaged, mirror like surface of CdTe crystals, they were subjected to chemi-mechanical polishing in a solution of $0.2 \mathrm{vol} . \%$ bromine in methanol. Prior to deposition of metallization, the native oxide was removed by soaking the samples in hydrazine hydrate for a time necessary to create highly hydrophobic surface [5].

Contact metallization was deposited by vacuum evaporation. In order to restrain the interaction of In with CdTe, some of the samples were capped with $200 \mathrm{~nm}$ thick rf-magnetron-sputtered $\mathrm{SiO}_{2}$. Heat treatments were conducted at temperatures ranging from 150 to $450^{\circ} \mathrm{C}$, in a conventional furnace under flowing $\mathrm{H}_{2}$ for times of up to 2 hours, and in a rapid thermal processing (RTP) system for $15 \mathrm{sec}$.

During annealing the cadmium release from In/CdTe structures was analysed by the thin film collector method [6]. Cr collectors were placed face-to-face on encapsulated or unencapsulated In/CdTe contacts. Finally, the amount of $\mathrm{Cd}$ accumulated in $\mathrm{Cr}$ collectors was evaluated by Rutherford backscattering method (RBS). The microstructure of the contacts was analysed by optical microscopy with Nomarski contrast, RBS and X-ray diffraction (XRD). Specific contact resistance was measured by four-point method.
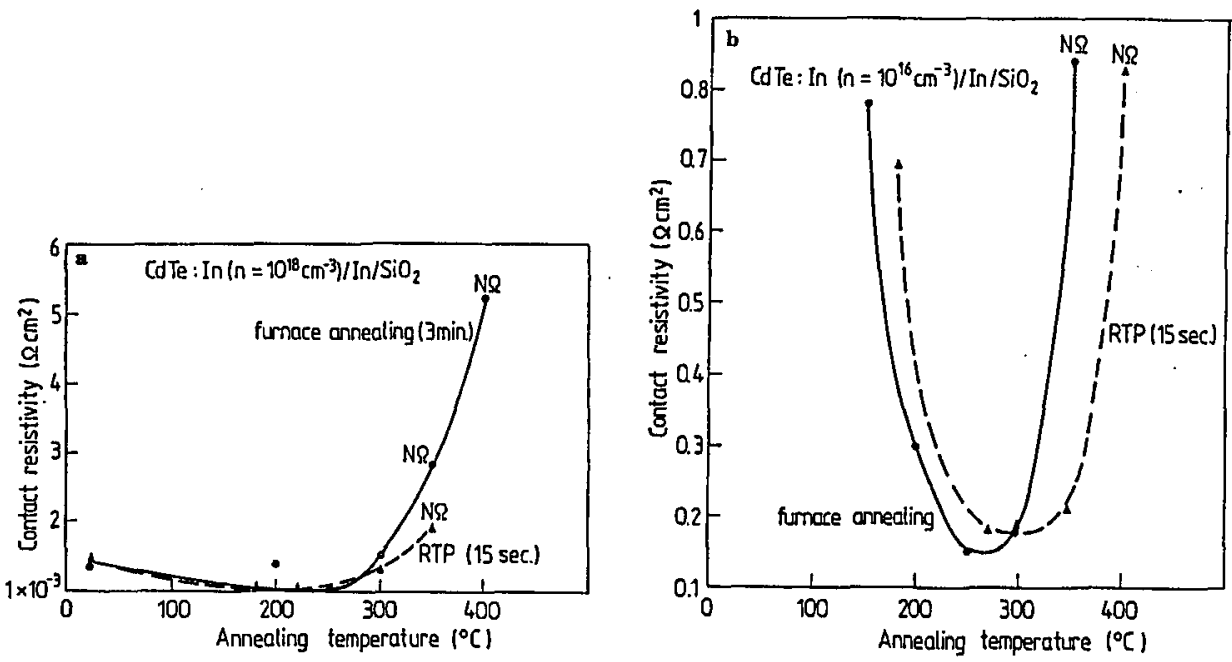

Fig. 1. The dependence of the specific contact resistance of In $/ n$-CdTe contacts on the temperature of heat treatment; (a) heavily doped $n$-CdTe, (b) lightly doped $n$-CdTe.

The specific contact resistance of $\mathrm{In} / n$-CdTe contacts as a function of annealing temperature is plotted in Fig. 1 . While the heavily doped $n$-type substrate $\left(n=10^{18} \mathrm{~cm}^{-3}\right)$ enables one to form an ohmic contact without any heat treatment (Fig. 1a), contacts deposited on lightly doped CdTe $\left(n=10^{16} \mathrm{~cm}^{-3}\right)$ require annealing at $200-250^{\circ} \mathrm{C}$ for $3 \mathrm{~min}$. or rapid thermal processing at $250-300^{\circ} \mathrm{C}$ 
(Fig. 1b). The minimum of the specific resistance of In contacts to SI CdTe was achieved after heat treatment at $250^{\circ} \mathrm{C}$ for 2 hours, and equaled $1 \times 10^{6} \Omega \mathrm{cm}^{2}$. Upon annealing the contacts above $300^{\circ} \mathrm{C}$ the specific contact resistance rapidly increases and finally the contacts exhibit non-ohmic characteristics.
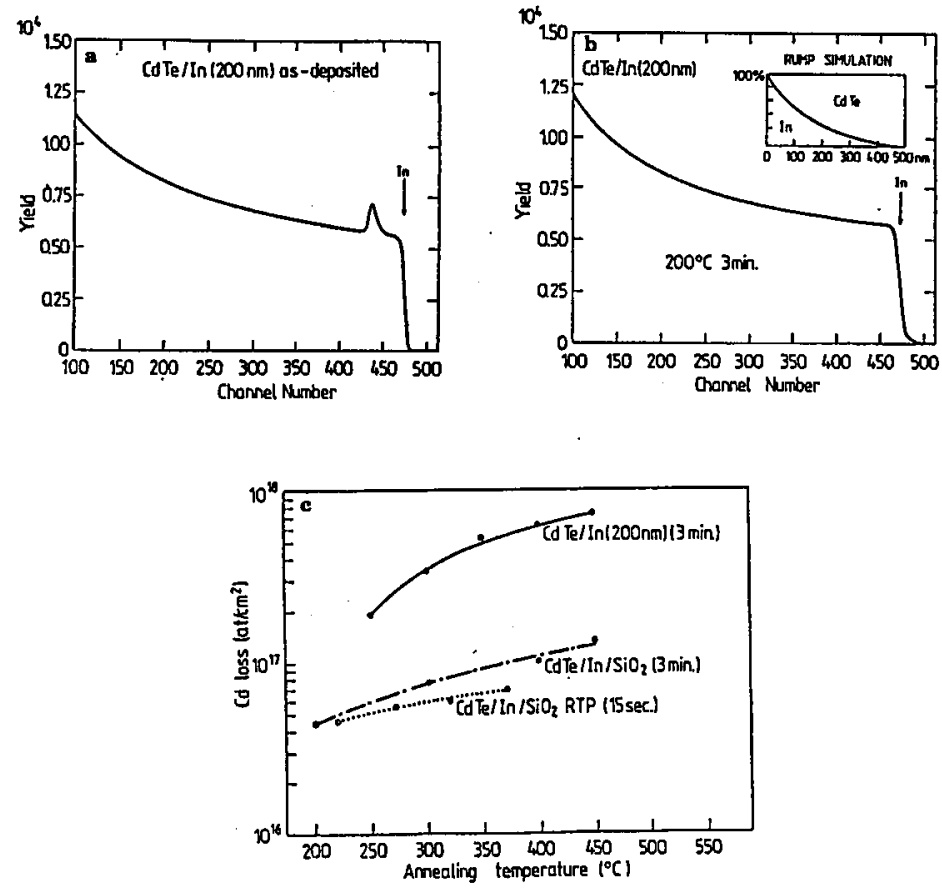

Fig. 2. $2 \mathrm{MeV}^{4} \mathrm{He}^{+} \mathrm{RBS}$ depth profiles and Cd losses during heat treatment of In/CdTe contacts; (a) RBS spectrum of the unprocessed contact, (b) RBS spectrum of the contact annealed at $200^{\circ} \mathrm{C}$ for $3 \mathrm{~min}$., and (c) Cd losses from capless, capped and RPT annealed contacts.

Figures $2 \mathrm{a}$ and $2 \mathrm{~b}$ show RBS spectra of the as-deposited and cap annealed In/CdTe contacts. According to the simulation, the intermixing of In and CdTe takes place as a result of heat treatment. However, no interfacial reaction between In and $\mathrm{CdTe}$ has been observed by XRD. As a result of annealing under a capping layer at $200^{\circ} \mathrm{C}$, the diffusion tail of $200 \mathrm{~nm}$ thick In metallization extends to the depth of $500 \mathrm{~nm}$ in CdTe film.

The total amount of cadmium losses from uncapped and $\mathrm{SiO}_{2}$-encapsulated contacts, heat treated in a conventional furnace as well as in a RTP system is shown in Fig. 2c. The most important release of cadmium occurs from contacts processed without a capping layer. The decomposition of semiconductor substrate and the out-diffusion of $\mathrm{Cd}$ are significantly reduced when annealing is conducted under a capping layer. Further suppression of $\mathrm{Cd}$ sublimation from the contact region can be achieved by using rapid thermal processing.

The technologically important aspect of In/CdTe interaction, during the formation of the ohmic contact, is the out-diffusion of $\mathrm{Cd}$ with subsequent creation 
of Cd vacancies, necessary for In to produce a highly doped subcontact region. Taking into account the experimental values of the specific contact resistance we can estimate, basing on a model proposed by Dingfen et al. [7], the doping level of $\mathrm{CdTe}$ beneath the contact to be in the low $10^{17} \mathrm{~cm}^{-3}$ range. This result is consistent with the low-temperature solid solubility data of $\mathrm{In}$ in $\mathrm{CdTe}$ [8]. The specific resistance of contacts formed on $n$-type CdTe:In is predominantly determined by the potential barrier between the metal and heavily doped subcontact region. In the case of contacts to SI CdTe, the specific contact resistance is controlled by the potential barrier between the heavily doped subcontact region and bulk material. The reason for the degradation of ohmic properties, when the contacts are heated above $300^{\circ} \mathrm{C}$, is probably the enhanced formation of $\mathrm{Cd}$ vacancies compared to the diffusion of In into them.

\section{References}

[1] M. Ohmori, Y. Iwase, R. Ohno, Mater. Sci. Eng. B 16, 283 (1993).

[2] J. Lajzerowicz, L. Verger, F. Mathy, M. Cuzin, Mater. Sci. Eng. B 16, 304 (1993).

[3] R.E. Braithwaite, C.G. Scott, J.B. Mullin, Solid State Electron 23, 1091 (1980).

[4] S. Nozaki, A.G. Milnes, J. Electron. Mater. 14, 137 (1985).

[5] P.W. Leech, private information.

[6] A. Piotrowska, E. Kamińska, S. Kwiatkowski, A. Turos, J. Vac. Sci. Technol. 73, 4404 (1993).

[7] W. Dingfen, W. Dening, K. Heime, Solid State Electron. 29, 69 (1986).

[8] E. Watson, D. Shaw, J. Phys. C, Solid State Phys. 16, 515 (1983). 